\title{
Information skills through electronic environments: considerations, pitfalls and benefits
}

Maggie Smart and Cath Hunt

The increasing availability of resources in electronic format has obvious benefits for distance learners in particular but, in order to maximise those benefits, library induction and ongoing support are essential. The use of virtual classroom sessions to provide library support to offcampus students is a relatively new concept: however, meeting students live online allows us to provide advice, guidance and training from induction through to completion of their studies. In this chapter, we describe our approach, discussing what has worked and what has been less successful as well as outlining some of our plans for the future.

\section{Background}

Salford is situated in north-west England, less than two miles from Manchester city centre. The University of Salford as we know it today has come together through a complex history of mergers and separations spanning well over 100 years. Throughout this time, it has retained strong links with industry, and partnerships with business, industry and the public sector remain important to Salford's teaching and research activities.

The University has a student population of around 18000 and a staff of over 2500. Part-time students account for approximately $23 \%$ of total student numbers overall but, on postgraduate taught programmes, part-time students outnumber full-time students.

Information Services Division (ISD) is responsible for library and information technology services at the University of Salford. The Schools (academic departments) at Salford are supported by dedicated ISD liaison teams, who work to ensure that the services ISD provides are appropriate. Liaison Officers in these teams are subject or IT specialists who support distance learners alongside the campus-based students in their Schools.

Over the past three years, we have worked with the School of the Built Environment to establish a new approach to library support for their internet-enabled MERIT research programme and we have recently extended this work to cover one of the School's taught postgraduate programmes, the MSc Real Estate \& Property Management.

\section{MERIT programme}

In January 2004, the School of the Built Environment added an internet-enabled, nonresidence $\mathrm{PhD}$ programme (the MERIT programme) to its portfolio. The programme has truly international reach, with students located in countries around the world, including Ireland, Canada, Saudi Arabia and UAE. At an initial meeting with the MERIT programme leader, before the first cohort of students registered, it was agreed that ISD would deliver two slots in the four-week induction. For this cohort, we kept the structure of the ISD sessions exactly as agreed in that first meeting. Since then, as our relationship with the School has developed, we have taken the lead in organising the sessions as we feel appropriate.

\section{Our use of electronic environments}

We deliver our sessions using Wimba Live Classroom in conjunction with Blackboard (Salford's virtual learning environment). e-Library forms an integral part of the library services we offer, providing access to the array of databases and other online information sources both on- and off-campus, and email plays an important role as a supporting means of communication. 


\section{Wimba Live Classroom}

The live virtual classroom, Wimba Live Classroom, supports audio, application sharing, text chat, polling and content display; with version 5, Live Classroom also offers a number of enhancements, including follow-the-speaker video and emoticons (icons such as smiley faces that act as emotional punctuation marks). Yet despite the array of features available, the requirements for taking part in a Live Classroom session are quite simple. Live Classroom talks about participants (students) and presenters (instructors) and the basic requirements currently specified by Wimba for both participants and presenters are shown in Table 1.

Table 1. Basic Live Classroom requirements

Computer with Windows 2000+, Mac OS X 10.2+ or Linux*

* Mac OS9 and Linux have limited features and functionality

$128 \mathrm{Mb}$ RAM (256 Mb recommended)

Web browser: IE 5.0+, Netscape 7.0+, Mozilla 1.0+, Safari 1.1+

(browser must be Java and JavaScript enabled)

Internet access at $56 \mathrm{k}$ or above

In addition, headphones or speakers are required to hear the audio and a microphone is required to take part in live conversation. Kirlew (2007), in his paper describing a pilot using Live Classroom at Virginia Commonwealth University Libraries, also discusses system requirements and the results of his evaluation.

\section{Blackboard}

Through Blackboard, students can download materials, interact with tutors and fellow students, submit work and check assessment results. All Salford modules have a presence on Blackboard and the modules that make up the MERIT programme are no exception. The extent to which Blackboard is exploited varies and the staff involved in the MERIT programme have worked hard to build a community spirit. As Grasman (2002) noted: 'Communication is the key to a successful internet-based course.'. We are both enrolled as instructors on the modules and, alongside the academic staff, we are able to add any material we feel is appropriate. The material we provide on Blackboard complements what we do using Live Classroom and includes interactive tutorials covering information search strategies, Boolean and critical evaluation. We also provide links to user guides and other ISD services. In addition, there is a link to our dedicated email address, which is monitored daily and which students use to contact us for advice and assistance.

\section{e-Library}

e-Library provides a single point of entry for accessing electronic (non-print) resources such as e-journals, e-books and databases. Users log in using their Salford network username and password. Useful features include the Multi-Search facility which allows federated searching, and My Area which allows users to customise e-Library to suit their particular requirements by saving database sets, searches and results, and to set up alerts. Because users are authenticated by logging in, they can check for any passwords they require to access specific resources.

\section{Live Classroom}

Drop out rates in distance education tend to be higher than campus-based courses, possible causes being feelings of isolation and lack of personal attention (Rovai 2002). The beauty of Live Classroom is that we can talk directly to the students - it allows us to replicate much of what we do with campus-based students who come in to the library for a group literature 
searching session or one-to-one. It helps to build relationships, to establish us as their point of contact for information support during their programme of study, and to promote use of ISD e-resources.

\section{A typical Live Classroom session}

The ISD element of the MERIT induction typically involves two Live Classroom sessions, which we run on separate days. The first session provides an introduction to ISD and eLibrary; in the second session we look at selected resources in more detail. We look primarily at the practicalities of locating and accessing appropriate resources and how to get the most out of the search facilities of the various databases. To help us plan suitable content, the School send us copies of the students' proposals, so that we are aware in advance of their broad areas of research. At the end of the first of the two sessions, we ask the students to log in to e-Library and access one of the databases before our second meeting, to check that their usernames and passwords are working correctly and that they know which password to use for what. Each session is scheduled for 90 minutes but, as with face-to-face sessions, the actual delivery time may vary, depending on the kinds of questions the students ask, how promptly they log in and whether any of them have technical problems.

One of the key aims of the Live Classroom sessions is to try and give the students the confidence to explore the resources at their disposal, in the knowledge that library support is available throughout their programme of study. We archive the sessions for students who were unable to log in, so they can see and hear everything that was covered but cannot interact.

\section{Factors influencing a session}

We have found that many of the factors influencing a Live Classroom session are similar to those we would take into account in planning a face-to-face information skills session.

- Timing: MERIT students may be based anywhere around the world, in different time zones, so co-ordination and forward planning are important; religious beliefs must also be taken into account. For UK-based students on the MSc Real Estate \& Property Management programme, timing is equally important, as the majority of them work full-time so evening sessions are essential.

- Location: it is important to have a room that is quiet (to avoid distracting background noise) and where sessions can be delivered without interruptions. We have also found it useful to have a telephone available, either to speak to the School technical support officer or, on rare occasions, to contact a student direct.

- Content: the MERIT programme usually consists of small groups of students and, having previously seen their proposals, we can tailor the content of the sessions accordingly. With the MSc group, because of the potentially much larger numbers of students, the content has to be much more generic with the emphasis on the range of sources available. We do, however, know that a law module forms part of the MSc programme, so we can include a demonstration of the Lawtel UK database for this group.

The majority of students on the MERIT programme are based overseas whereas the MSc students are UK based. This means that, with the MSc group, we can publicise and encourage them to use our document supply service and make them aware of additional facilities at their disposal such as the UK Libraries Plus scheme. The 
MERIT students all have a local advisor in addition to their Salford supervisor and this means they have access to advice about what might be accessible locally.

- Technical competence: students vary widely in levels of confidence and competence in using the Live Classroom system; for us, the School's technical support officer is generally on hand to resolve individual problems in the background as we continue to deliver a session. On occasion, if a student seemed to be having difficulty, we have found it useful to split a single 90-minute session into two shorter sessions.

\section{Managing the technology}

As with equipment in a lecture theatre, using Live Classroom in an effective way depends on becoming familiar and confident with the system. There is documentation available from Wimba, and the Wimba User Group is another source of support. Live Classroom provides a Setup Wizard which helps to identify many potential problems that might interfere with a session so it is important that both presenters and participants run this before logging in. At present we use only a subset of the features that are actually available in Live Classroom, focusing on the content frame to share PowerPoint slides, application sharing for the resource demonstrations, text chat and, of course, audio so that we can converse with the students. The 'lock talk' feature ensures that our presenters' microphone is locked on, leaving our hands free to use the keyboard and mouse for the demonstrations.

On a practical level, one of the things we do when delivering a session is to have a laptop logged in via our wireless network to help us with timing. Screen refresh is not always instantaneous and this acts as an indicator of what the students might see on a slower connection - therefore helping us to pace each session appropriately. For the resource demonstrations, we open a new window rather than using the content frame in Live Classroom, so that as much of the screen as possible is visible without having to scroll up and down.

\section{Teaching and learning styles and fostering interaction}

We use a combination of demonstration and commentary which should appeal to both auditory and visual learners, and we try, with varying degrees of success, to involve the students by asking them to suggest their own search terms and topics in addition to the ones we have prepared. We also encourage them to ask questions at regular intervals throughout the sessions, and these tend to vary between enquiries about database functionality to questions about their research topics. The fact that the questions are asked via Live Classroom rather than email means that all the other participating students can benefit as well.

We have found that two presenters are far more effective than one, as the change of voice and pace helps to maintain interest. We also use a boundary microphone, which eliminates the need for individual microphones and helps to bring a conversational element to the session. Although these may seem very simple factors, they make a huge difference to the tone and quality of a session. As Ronayne \& Rogenmoser (2002) found when using interactive television for library instruction: 'Just having both librarians up front together immediately raised the energy level and created a more dynamic classroom climate. Interaction with students increased...'.

Many students prefer to learn through practical experience, so we encourage them to try out at least one of the databases in their own time between sessions and we remind them to use the interactive tutorials on Blackboard. The archives of the sessions are useful not only for students who were unable to attend the live session, but as a 'refresher', particularly helpful for international students whose first language is not English. 


\section{Managing interpersonal issues}

As with any kind of group instruction, it is possible that problems may arise if, for example, the input of a particularly dominant student starts to have a negative impact on the other participants. The groups we work with at present are generally small and comprise postgraduate students who are highly motivated and professional. So far we have not encountered major problems but the fact that we co-present the sessions means that one of us could deal with an issue individually while the other continued to deliver the session. In effect, the same strategies we use in a face-to-face session can be applied to the virtual classroom - first by trying to incorporate the comments or questions, then taking the individual student aside by using the text chat frame and, finally, dealing with matters outside the classroom if necessary.

\section{Is the virtual classroom worth the effort?}

Using Live Classroom has required investment from the School in hardware and technical support, and changes and challenges for the academic staff and for us in adapting to a new way of teaching and learning. Having worked with the system for over three years, we can now step back and begin to assess whether that investment has been worthwhile.

Distance learners, whether they are separated from the institution by time or distance, pay significant sums of money to undertake their studies. As they are studying to the same level and for the same qualifications as traditional campus-based students they require and are entitled to equivalent library resources and support. The Live Classroom sessions go some way towards redressing the balance between what is offered to on-campus students (the full range of services and resources including group and one-to-one help from their Liaison Officer) and distance learners who are unable to visit the University in person.

\section{Feedback and evaluation}

Clayton (2004) highlights the importance of formal evaluation in order to collect and collate students' views on the usefulness of the training they received. When we first started delivering sessions on the MERIT programme we relied on feedback from the programme staff and, quite early on, had a formal review meeting with the programme director. After that meeting, we set about trying to carry out more formal evaluation, looking not just at immediate comments after the session but also trying to evaluate the longer term impact have the students continued to use the e-resources and, if not, why not? We have tried several approaches, including short email questionnaires and, more recently, an online evaluation form with a link from Blackboard, but without success. One reason for this may be the lack of time for refection and the inbuilt reluctance that we feel ourselves in similar situations, but we are determined to persevere and our future plans include devising new approaches to evaluation.

On the other hand, spontaneous feedback from the students has been extremely positive and this has come to us directly and also via the School staff (both academic and technical). Partly as a result of the students' comments after our recent sessions for the MSc Real Estate \& Property Management, ISD sessions will form an integrated part of that programme from the start of the new academic year.

In our experience the benefits of using Live Classroom far outweigh the limitations. As well as introducing the students to the resources they will need and building the relationships that mean they know where to come for assistance, the sessions have also helped to raise awareness of the wide range of library resources among staff in the School. 


\section{Future directions}

We have a number of plans for the future, ranging from exploration of new features in Live Classroom to establishing our own dedicated space in the library for development work and delivering sessions.

- We would be interested to investigate closer integration of Live Classroom into Blackboard. Currently the two operate separately at Salford but are used to complement each other.

- We intend to evaluate some of the features that we have not yet used, including those that are new in Live Classroom 5, for example, follow-the-speaker video which is a voiceactivated and automatically displays the image of the current speaker. This allows instructors and students alike to put faces to names and might help to provide a more direct indication of student engagement.

- We aim to follow up different approaches to evaluation. For example, students will be able to give feedback during live sessions using the emoticons - could we make use of this feature for evaluation purposes? We are also considering allowing time towards the end of sessions for students to complete the online evaluation, whilst bearing in mind the importance of time for reflection.

- Irrespective of whether you are delivering an online or face-to-face session, it can be easy to deter students by off-the-cuff searches that yield either no results or thousands of results that seem only vaguely relevant. Set against this are the benefits of spontaneous interaction and using that spontaneity as part of the learning process: not everything works first time and the answer lies in learning how to refine a search, rather than giving up. So one of our resolutions is to be bolder and turn the things that don't quite work into a learning experience.

- Since we embarked on Live Classroom, we have delivered our sessions from several different rooms in the library. We are now optimistic that we can justify investment in a dedicated room that will provide a fixed base for delivering sessions and also a space where we can experiment and work with colleagues to develop new approaches - in particular finding new ways of making the sessions more interactive.

- We plan to offer more regular updates, keeping students informed about changes to the services we provide (e.g. new databases, new journals, changes to access methods). However, we are aware of the need to do this efficiently while taking into account the many other demands on our time.

For us, delivering live virtual classroom sessions has opened up new possibilities by extending the ways in which we can support Salford students, wherever they are located. We are confident that other groups of students could benefit and there is considerable enthusiasm amongst our colleagues to find out more about Live Classroom. We have learned a lot in the course of our work over the past three and a half years - and we are looking forward to doing and learning more.

\section{References}

Clayton, S. (2004) Your class meets where? Library instruction for business and education graduate students at off-campus centers. Reference Services Review. 32 (4), 388-393. 
Grasman, S.E. (2002) Teaching Engineering Economics via Distance Education. In Proceedings of the 2002 American Society for Engineering Education Annual Conference \& Exposition, 5935-5939.

Kirlew, P. (2007) Enhancing synchronous online library instruction services in Blackboard using the Wimba Live Classroom system. Special Libraries Association. http://www.sla.org/pdfs/sla2007/kirlewonlinelibinstrsvcs.pdf

Ronayne, B and Rogenmoser, D. (2002) Library research instruction for distance learners: an interactive, multimedia approach. In Brophy, P., Fisher, S. and Clarke, Z. Libraries without Walls 4: the delivery of library services to distant users: proceedings of an international conference held by the Centre for Research in Library and Information Management (CERLIM) Manchester Metropolitan University, Facet Publishing.

Rovai, A. (2002) Building sense of community at a distance. International Review of Research in Open and Distance Learning, 3 (1) 74-85. 